\title{
Cerebral Angiography: The First Small Step for the Neurointerventionist
}

Jae Ho Shin, MD, $\mathrm{PhD}$

Department of Radiology, St. Vincent's Hospital, The Catholic University of Korea, Suwon, Korea
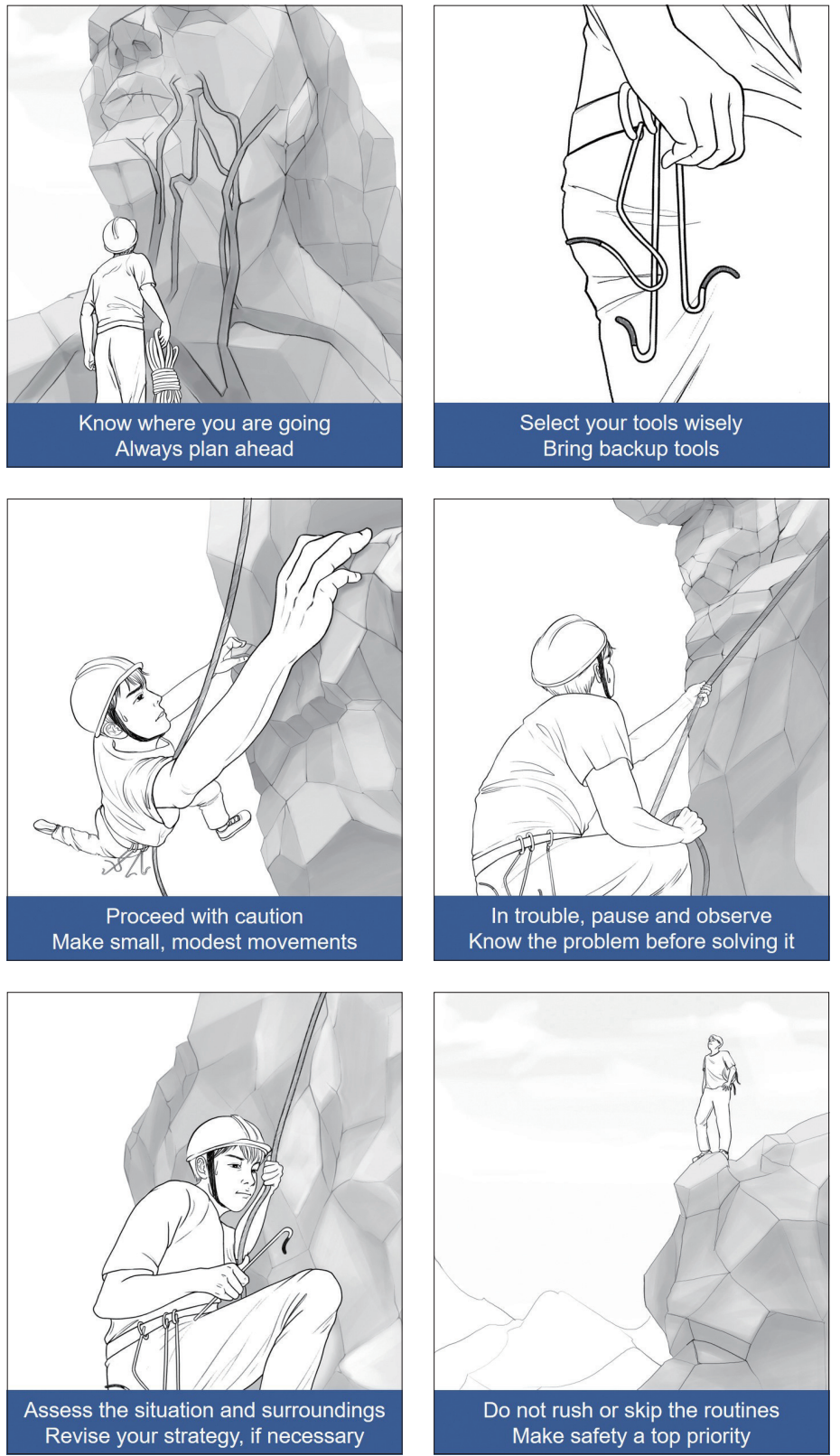

\section{Correspondence to:}

Jae Ho Shin, MD, PhD

Department of Radiology, St. Vincent's Hospital, The Catholic University of

Korea, 93 Jungbu-daero, Paldal-gu,

Suwon 16247, Korea

Tel: +82-31-249-7492

Fax: +82-1577-8588

E-mail: ciprofloxashin@hotmail.com

Received: March 25, 2020

Revised: April 24, 2020

Accepted: May 7, 2020
Copyright $\odot 2020$ Korean Society of Interventional Neuroradiology

This is an Open Access article distributed under the terms of the Creative Commons Attribution Non-Commercial License (http://creativecommons.org/licenses/by-nc/4.0) which permits unrestricted non-commercial use, distribution, and reproduction in any medium, provided the original work is properly cited. 
There comes a moment when you first perform a solo cerebral angiography successfully. It is as thrilling an experience as the first time you drive your own car without your worrying parents riding along. The sense of accomplishment is absolutely exhilarating, and I believe it is this first small step that transforms physicians into neurointerventionists. In this article, I would like to share some advice and guidance that I learned as a first-year fellowship trainee in performing cerebral angiographies. Instead of focusing too much on the technical aspects of cerebral angiographies, I would like to focus on other considerations, the ones that are often overlooked, yet are critically important to performing successful angiography.

The first step is to know why and where you are performing cerebral angiography. Why is this patient getting the angiography? What are the patient's history and symptoms? These philosophical questions of "why" and "where" prepare you mentally and put you in the proper mind-set to establish a plan of action as to which cerebral vessels to perform angiography, how much contrast media is going to be needed, and what type of view is going to be acquired. 'Otherwise, a "blind" cerebral angiography is performed and no useful information may be acquired, while your patient may have experienced one of the most painful procedures all for nothing. As my professor used to say, "Patients are not subjects. Know why and where you are going."

The second step is to select your tools wisely. Selecting proper tools based on a patient's age, aortic arch configuration, height, and underlying vascular anomalies can make the difference between a successful angiography and an agonizing failed angiography. Numerous tools are used in angiographies, ranging from catheters to wires, each with different calibers, lengths, tip shapes, and stiffnesses. We take comfort in using catheters that are most familiar to us. However, when you encounter a tortuous path or a dead end, it is necessary to step out of your comfort zone and use other, unfamiliar tools that can help guide your way. Therefore, familiarize yourself with all of them and get to know them well. Otherwise, you will end up changing catheters more than necessary ${ }^{2}$ and prolonging the angiography procedure, which may increase the chance of complications. ${ }^{3}$

The third step is to pause and observe. When you are in predicament, you need to stop what you are doing and just simply survey the situation because it is better to observe than to do something mindlessly. Therefore, stop immediately, assess the situation, and ask: Why does that ves- sel look like that? Why does my angiography look different from the previous angiography? Why is my wire bending like this? Why is my catheter not moving? You need to contemplate what is happening so that you can revise your strategy and have better information when it comes time to make a decision. Otherwise, you will end up creating more problems than you solve.

The fourth step is to treat vessels very gently, delicately, and with great care. Always advance the wire first, and then follow with smooth catheter advancement. Do not use extreme force or make abrupt motions; instead, make small, modest movements and be graceful like a brush stroke on a canvas. Feel the vascular pulsation and the tactile feedback from the catheters. 'Try to avoid obstacles, such as dissections, stenoses, aneurysms, and troublesome calcifications on the vessel wall. If obstacles are unavoidable, an ethical decision must be made based on the diagnostic benefits of cerebral angiography balanced with the potential complications.

The fifth step is to look around and take care of your surroundings, making sure that your patients and your tools are okay and functioning optimally. Performing the cerebral angiography is one thing, but taking care of your patients is another thing. You must pay attention to your patients and your tools because nobody else will! Your patients are probably nervous and afraid right now, unless they are under anesthesia. Talk to them. Explain to them what they are going through and empathize with them. Not only will it alleviate unwarranted fear, but also cognitive and neurological function can be assessed at the same time. Ask, how are you feeling? Are you breathing okay? Also, there is no shame in being over-attentive to your surroundings, because chances are, your cerebral angiography will be successful, and your patient will be fine. Don't fixate too much on the angiography screen; look around and check to see if anything is out of order.

The last step is to proceed at your own pace and follow the routine, no matter what. Performing cerebral angiography on tortuous vessels can be stressful. We can be tempted to rush in and try to finish it quickly so that we can catch our breath and get a coffee break. However, haste, careless procedures, and skipping routines are a recipe for disaster. Slow it down. Always follow the routine. Make a roadmap. Lastly, when everything seems not to be working, for whatever the reasons may be, it is important to just call it a day or ask for help. Do not hesitate to ask for help and be honest about 
your current situation so that any potential problems can be solved swiftly to avoid inadvertent complications. We are used to thinking that success depends on confidence and perseverance, but sometimes in cerebral angiography, success may depend on humility and compromises. Let us not forget that there is a patient lying on the angiography table. It is not about how skillful you are, rather it is about getting it done safely without risking the patient's well-being. ${ }^{4} \mathrm{My}$ professor used to say, "Do not try to make a beautiful, perfect angiography. Leave it as is."

As a closing remark, cerebral angiography is a small step for the neurointerventionist but at the same time, a giant leap for the neurointerventionist. As ironic as it may sound, this "small" step requires much practice, preparation, reviews of cerebral angiographies, and the help of professors and technologists.

\section{Fund}

None.

\section{Conflicts of Interest}

The author has no conflicts to disclose.

\section{ORCID}

Jae Ho Shin: https://orcid.org/0000-0001-5922-5720

\section{REFERENCES}

1. Ahn SH, Prince EA, Dubel GJ. Basic neuroangiography: review of technique and perioperative patient care. Semin Intervent Radiol 2013;30:225-233

2. Earnest F 4th, Forbes G, Sandok BA, Piepgras DG, Faust RJ, Ilstrup DM, et al. Complications of cerebral angiography: prospective assessment of risk. AJR Am J Roentgenol 1984;142:247253

3. Citron SJ, Wallace RC, Lewis CA, Dawson RC, Dion JE, Fox AJ, et al.; Society of Interventional Radiology; American Society of Interventional and Therapeutic Neuroradiology; American Society of Neuroradiology. Quality improvement guidelines for adult diagnostic neuroangiography. Cooperative study between ASITN, ASNR, and SIR. J Vasc Interv Radiol 2003;14(9 Pt 2):S257-S262

4. Shin DS, Yeo DK, Hwang SC, Park SQ, Kim BT. Protocols and results of resident neurosurgeon's transfemoral catheter angiography training supervised by neuroendovascular specialists. J Korean Neurosurg Soc 2013;54:81-85 